\title{
LA PROPENSIÓN EXPORTADORA DE LA ECONOMÍA SOCIAL ANDALUZA Y SUS DETERMINANTES
}

\section{EXPORT TREND OF ANDALUSIAN SOCIAL ECONOMY AND ITS DETERMINANTS}

Pérez Suárez, Macarena (Universidad de Sevilla) *

Espasandín Bustelo, Francisco (Universidad de Sevilla) **

Sánchez Torné, Isadora (Universidad de Sevilla) ${ }^{* * * *}$

\section{RESUMEN}

Este trabajo tuvo como objetivo determinar los factores internos (tamaño, presupuesto de innovación, ventas en el exterior y comercio electrónico) y los factores externos (sector económico) que condicionan la propensión exportadora de las cooperativas y sociedades laborales andaluzas. Se planteó un método inductivo bajo un análisis estadístico e inferencias en un límite territorial, Andalucía, y en dos momentos puntuales del tiempo, 2002 y 2013. Los resultados probaron un incremento de la propensión exportadora de las empresas de Economía Social andaluzas y, especialmente, entre las entidades del sector primario y de mayor dimensión empresarial.

Palabras claves: Exportación, cooperativas. JEL: F43, P13.

\section{ABSTRACT}

This work aimed to determine the internal factors (size, budget innovation, overseas sales and e-commerce) and external factors (economic sector) which affect the export propensity of cooperatives and worker-owned companies. We used an inductive method under a statistical analysis and inferences in a territorial limit, Andalusia, and two specific years, 2002 and 2013. The results proved an increase in export propensity of enterprises Andalusian Social Economy and especially among entities in the primary sector and greater business dimension.

Key words: Export, cooperatives. JEL: F43, P13.

\section{INTRODUCCIÓN}

La apertura al exterior es una realidad de la economía española. Desde principios del siglo XXI, el tejido empresarial ha experimentado un proceso progresivo y generalizado de internacionalización en el que las empresas han jugado un papel destacado; a pesar de ser en su mayoría un tejido empresarial de PYMES y empresarios individuales, cuya dimensión tiende a orientar su producción al ámbito local o a lo sumo regional (Romero y RodríguezGutiérrez, 2014).

* Departamento de Economía Aplicada III, Facultad de Ciencias Económicas y Empresariales, Avda. Ramón y Cajal, s/n, 41018, Sevilla. mperez32@us.es

** Departamento de Administración de Empresas y Comercialización e Investigación de Mercados (Marketing), Avda. S. Francisco Javier, s/n, 41018, Sevilla. bustelo@us.es

*** Departamento de Economía Aplicada III, Facultad de Ciencias Económicas y Empresariales, 41018, Avda. Ramón y Cajal, s/n, 41018, Sevilla. isanchez6@us.es

Recibido: Marzo de 2016. Aceptado: Mayo de 2016. 
Según Gutiérrez, Morán, Belda, Sánchez-Torné y Pérez-Suárez (2014), aunque desde finales de 2009, la actividad exterior ha sido motor de la economía española y andaluza, el nivel de internacionalización de ambas economías no ha permitido que la contribución al crecimiento haya sido significativa y, en el caso andaluz, éste posiblemente motivado por las características de la actividad exterior: clara preponderancia de los intercambios dentro del territorio, escaso nivel de transformación y valor añadido, fuerte peso del sector agrícola/agro industrial, arraigado del minifundio empresarial, menor desarrollo tecnológico y escasa diversificación de la producción industrial.

Andalucía cuenta con una balanza comercial deficitaria y más estancada que la española, en la que sobresale el sector agroalimentario (Cortés, 2001), con un mayor dinamismo en las provincias de Cádiz - principal exportadora e importadora- Huelva y Sevilla, y cuyos principales países de destino de las exportaciones son Francia, Alemania, Reino Unido, Portugal e Italia.

La internacionalización de las empresas es, sin duda, una decisión estratégica, especialmente cuando se pierde cuota de mercado interior y se gana en el mercado exterior (Fariñas y Jaumandreu, 1995). En palabras de Moral y Lanzas (2009), la internacionalización de las empresas favorece la innovación, la especialización y el aprovechamiento de economías de escala. Al mismo tiempo que el comportamiento exportador está condicionado por diferentes factores internos y externos a las empresas.

La empresa española sigue un proceso de internacionalización de tipo evolutivo (Galán, González y Galende, 2000); en el que la experiencia exportadora le permite obtener el conocimiento institucional y competitivo necesario para avanzar en el proceso de internacionalización. Y es que la exportación es el modo más popular y primario de internacionalización, utilizado principalmente por las empresas de menor tamaño relativo, puesto que, en palabras de Leonidou, Katsikeas y Samiee (2002), requiere menor cantidad de recursos financieros, humanos, etc., e implica un riesgo menor. Según datos del ICEX España Exportación e Inversiones, las empresas exportadoras en el año 2014 ascienden a 147.731; siendo las tres cuartas partes $(73,4$ por 100$)$ pequeñas empresas exportadoras que facturan menos de $50.000 €$ anuales.

Por otra parte, la Economía Social proporciona herramientas de actuación muy reveladoras, derivadas de sus propias características y estructuras empresariales, que permiten afrontar con éxito los cambios sociales y las crisis económicas (Pérez y Jiménez, 2012). El modelo de Economía Social es vital para estimular el desarrollo local y regional (Pérez y Carrillo, 2000) y no está exento de competir en el mercado global, si desea garantizar su sostenibilidad económica, social y ambiental.

En el caso particular del cooperativismo español, desde hace algunos años, el volumen exportador es relevante, sobre ello Fuentes, Sánchez y Santos (2011) apuntan que: “en 2009, el 35\% de las cooperativas españolas vendían en otros países de la Unión Europea (...). La implantación exterior de las cooperativas españolas es escasa (...), suele presentar un escaso interés por la internacionalización, derivado de problemas de dimensión y formación empresarial", como ya se señalaba anteriormente que sucede en Andalucía.

Además, resaltamos la importancia excepcional de la Economía Social como sector generador de empleo, renta y riqueza de características propias. Tanto es así que, en 2001, la Economía Social andaluza representaba más del 12 por 100 del PIB andaluz, según expone CEPES-Andalucía en su informe anual de 2001, y al finalizar 2013, el 13 por 100 del PIB andaluz, según fuentes de la administración pública regional. A lo que hay que añadir, que su comportamiento en los actuales tiempos de crisis, está dando una respuesta menos desfavorable que la economía tradicional capitalista en parámetros como, por ejemplo, la 
destrucción de empleo (Pérez y Jiménez, 2012). En la economía andaluza, las cooperativas y las sociedades laborales son las formas jurídicas principales, agentes capaces de aglutinar la función económica de crear riqueza con eficiencia y la función social de distribuirla con equidad (Millán y Melián, 2008).

En relación a la actividad exterior de las empresas andaluzas, Jordá y González (2009) comprueban que, además de la exportación, utilizan más de una vía de internacionalización, y que las empresas innovadoras se introducen en el proceso de internacionalización mediante diversas formas (exportación directa, exportación indirecta a través de distribuidoras comerciales, inversión directa, proyectos de I+D, etc.). La Federación de Cooperativas de Trabajo Asociado (Faecta, 2007) identifica como principales mercados de exportación de la Economía Social: Francia, Reino Unido y Portugal, además de otras áreas de desarrollo económico, como Marruecos o Polonia.

El fenómeno de la internacionalización de las empresas, y específicamente de la exportación, ha tenido un amplio eco en el ámbito académico (Martín, Rastrollo y González, 2009) y se ha convertido en materia de estudio indispensable para el área de negocios internacionales (Tabares, 2012). La investigación desarrollada presenta, entre otras, características análogas, pues los estudios que se realizan se integran en tres grandes grupos: los teóricos y de encuadre metodológico; los que se han realizado sobre aplicaciones prácticas en países asiáticos y los estudios empíricos vinculados a la internacionalización empresarial.

En palabras de González (1999), la mayoría de las investigaciones sobre la actividad exportadora se lleva a cabo a partir de datos de corte transversal, y la información disponible sobre la actividad exterior es, casi exclusivamente, de ámbito macroeconómico (De Lucio, Mínguez y Álvarez, 2007). Según Herrero y Sanz (2003), la información disponible sobre la internacionalización de las empresas ha sido tradicionalmente muy escasa en España y en el resto del mundo; además, ofrece una visión parcial de sectores económicos, empresas y territorios específicos, y presenta sesgos en la formulación de las preguntas y en las respuestas que ofrecen las personas entrevistadas.

Por otra parte, existe un déficit de estudios centrados en analizar las causas que motivan el resultado exportador en empresas no anglosajonas; déficit que se acentúa cuando el sistema objeto de estudio es la Economía Social. Es por ello que la investigación sobre este ámbito carece de fundamentos conceptuales completos, ofrece una mayoría de estudios descriptivos y exploratorios, con una tendencia a replicar; lo que ha provocado que el tópico científico se encuentre todavía en etapa de identificación y conceptualización (Leonidou, 1995).

En síntesis, dos son los motivos que justifican esta exploración: en primer lugar, subsanar las carencias que existen en la literatura sobre investigaciones con un carácter explicativo y longitudinal sobre el tópico "actividad exportadora" $\mathrm{y}$, en segundo lugar, subsanar los déficits de conocimiento sobre el desarrollo de la actividad exportadora en el ámbito de las empresas de Economía Social de Andalucía.

Consecuentemente, el objetivo general es generar conocimiento útil y destinarlo, principalmente, a los órganos directivos de las cooperativas y sociedades laborales andaluzas, para que, mediante la comprensión de la propensión exportadora de la Economía Social andaluza y los factores (internos y externos) que la condicionan, puedan tomar mejores decisiones sobre su actividad internacional. Al mismo tiempo, puede ser de utilidad para grupos de interés académico, político y sectorial.

Para conseguir el objetivo general planteado, se toma como punto de partida el paradigma de la Economía Industrial (Buesa y Molero, 1998), que trata la relación entre estructura de los mercados-conducta de las empresas y resultados; y la teoría de recursos y capacidades (Barney,1991), que permite identificar los recursos y capacidades que permiten 
explicar el grado de propensión exportador. Además, los enfoques de internacionalización implicados son de índole económica, secuencial y estratégica.

En lo que se refiere a las características de la investigación, aclaramos que es de tipo descriptivo, explicativo, longitudinal y exploratorio, y que se estructura en los cinco apartados siguientes: en primer lugar, se desarrolla el marco teórico, se plantean y justifican las hipótesis y se diseña el modelo conceptual; en segundo lugar, se describen los métodos de captación y análisis de datos; en tercer lugar, se presentan los resultados, para finalmente detallar y discutir las conclusiones, acompañadas de limitaciones y futuras líneas.

\section{REVISIÓN DE LA LITERATURA. FORMULACIÓN DE HIPÓTESIS Y PLANTEAMIENTO DEL MODELO CONCEPTUAL}

En este apartado, se formulan las hipótesis que van a ser objeto de contrastación y que integran el modelo conceptual de este trabajo. Por su parte, la literatura consultada propone diferentes variables e indicadores para medir el resultado exportador. En palabras de Morgan y Katsikeas (1998) la práctica exportadora es el resultado de las ventas internacionales de una empresa e incluye tres subdimensiones: ventas, rentabilidad y crecimiento de las exportaciones.

Con carácter más específico, la literatura consultada propone medir el resultado exportador en base a indicadores como la propensión exportadora (Bilkey, 1978), la intensidad exportadora o la probabilidad exportadora (López, 2004), el desarrollo exportador (González, Navarro y Peña, 2010), la actitud frente a la exportación (Grisprud, 1990) o el tamaño medio de las exportaciones (Berthou y Vicard, 2013). Aunque con reticencia por no reflejar la dimensión competitiva del éxito exportador, el indicador más utilizado en la literatura es la propensión exportadora, que se define como el cociente entre las ventas realizadas en los mercados exteriores y la producción total de cada empresa.

En palabras de Fernández (2013), el sector exportador de la economía española ha registrado una evolución positiva en los años de crisis económica, motivado por la tendencia creciente de las ventas al exterior y la proporción de empresas exportadoras. Corroborando a López (2004), quien concluye que las empresas pequeñas y grandes han duplicado su propensión exportadora. A la luz de las evidencias referidas se formula la siguiente hipótesis.

\section{H1. La propensión exportadora de las empresas de Economía Social andaluzas aumenta en el horizonte temporal $2002-2013$.}

El resultado exportador es consecuencia de múltiples factores interrelacionados. La identificación y definición de estos factores o estímulos es un tema prioritario para los investigadores que estudian la internacionalización de las empresas (Bilkey, 1978; Aaby y Slater, 1989; Zou y Stan, 1998; López, 2004; Monreal, 2009).

Habitualmente esos factores se clasifican, atendiendo a su origen, en externos (entorno general, sector, políticas de promoción de cada gobierno...) e internos (tamaño, calidad de los productos, antigüedad, forma jurídica, características de los directivos o percepciones de éstos sobre la actividad exportadora...). También se suelen clasificar por su naturaleza en: proactivos (el aprovechamiento de economías de escala, la producción de bienes con características únicas o la identificación de las mejores oportunidades en el exterior...) y reactivos (la acumulación de inventarios no vendidos en los mercados domésticos, la capacidad de producción no utilizada, la intensa competencia en el mercado local...).

Aunque los factores que se consideran más determinantes son de carácter interno y proactivo, diversos estudios (Lu y Beamish, 2001; Westhead, Binks, Ucbasaran y Wright, 2002; Arias, 2004; Oviatt y McDougall, 2005) destacan el papel principal del sector en el que 
la empresa opera, o quiere operar, como factor determinante del resultado exportador. La investigación pone de manifiesto que la dinámica y la tradición exportadora del sector económico es un condicionante claro; así, López-Duarte y García-Canal (1998), entre otros factores, resaltan que el resultado exportador es superior en los sectores financiero y agroalimentario. La consideración de las ideas previas y el hecho de que el sector agroalimentario es un sector estratégico en Andalucía, responsable a nivel nacional de más del 20 por 100 del total de productos alimenticios vendidos al año en mercados internacionales entre 1995 y 2005 (Moral y Lanzas, 2009), invitan a formular la siguiente hipótesis.

H2. El sector agrario de la Economía Social andaluza presenta la mayor propensión exportadora, en los años 2002 y 2013.

Las cooperativas agrarias son claves de desarrollo del sector. Andalucía lidera el número de cooperativas, socios y facturación en España durante sucesivos años, además de destacar por la ganadería, frutas y hortalizas (Juliá y Marí, 2003). Ello acontece unido a la actividad exportadora y a un sector agroalimentario que conduce el mercado nacional, es decir, es un sector que aporta un importante valor añadido bruto industrial, con una cifra de negocios agregada que superó los 4.000 millones de euros en 2013 (KMPG, 2015).

En estrenadas declaraciones, el Presidente de CEPES-Andalucía (2015) incidía en el avance y la competitividad exterior de las cooperativas agrarias andaluzas. Particularmente, Fernández, Peña y Hernández (2008) ya se centraron en comprobar la relación directa entre los resultados económicos y la práctica exportadora en las cooperativas vitivinícolas. Mientras que, Fuentes, Sánchez y Santos (2011) estudiaron los mercados en los que operan y los canales que utilizan en la apertura exterior las cooperativas agroalimentarias españolas.

Recientemente, Medina, Mozas, Bernal y Moral (2014) exponían que exportar ha pasado a convertirse en un requerimiento de crecimiento y competitividad para las cooperativas oleícolas y, en ello, declaran la existencia de una serie de variables que influyen positivamente en la práctica exportadora. Mientras que Fayos y Calderón (2013) afrontaron la problemática de la actividad internacional también de las cooperativas agroalimentarias, identificando barreras externas (competencia y la estructura de la distribución) e internas (recursos financieros, imagen y marca, desarrollo e investigación), y adelantando una serie de mejoras como incrementar el tamaño.

H3. El tamaño de las empresas de Economía Social andaluzas influye en su propensión exportadora en los años 2002 y 2013.

Posiblemente, el tamaño es el factor sobre el que más ha incidido la literatura económica que trata la internacionalización de las empresas en la última década (Correa-López y Doménech, 2012), debido a su relevancia a la hora de conseguir ventajas competitivas. Normalmente, las variables e indicadores que se utilizan para medir el tamaño son el volumen de ventas, el volumen de activos o el número de empleados.

Desde un punto de vista normativo, el tamaño ejerce un efecto positivo en la propensión exportadora, puesto que las empresas de mayor tamaño cuentan con más recursos y capacidades, pueden conseguir economías de escala, perciben menos riesgos en sus operaciones internacionales, tienen más y mejores oportunidades de financiación, maximizan su poder de compra o negociación, tienen más facilidad para acceder a la información y son más eficientes en las actividades de producción y distribución (Reid, 1982; López, 2004). En sentido similar, Bonaccorsi (1992), Calof (1994), Nakos, Brouthers y Brouthers (1998), Dean, Mengüç y Myers (2000), Nassimbeni (2001), Melle y Raymond (2001) confirman la existencia de cierta linealidad entre el tamaño de la empresa y su creciente actividad exterior. 
La investigación pone de manifiesto que la relación entre tamaño y propensión exportadora puede tener un carácter ambiguo, puesto que esta relación puede llegar a ser inversa cuando, una vez acotada la demanda interna, las pequeñas empresas sólo pueden crecer al orientarse a los mercados exteriores. En el mismo sentido, Moreno y Rodríguez (1998) concluyen que la propensión exportadora crece a medida que aumenta el tamaño de la empresa, pero hasta un cierto nivel, a partir del cual, la propensión exportadora decrece. Idea apoyada y verificada por Alonso (1994), Alonso y Donoso (1998), Bonaccorsi (1992) y Centrale (1997) cuando afirman que la facturación exportada más alta tiende a observarse en los tramos intermedios de tamaño.

Se detecta, por tanto, una definición teórica de la relación entre tamaño y propensión exportadora que puede dar lugar a resultados inconsistentes, dado que la relación postulada a priori entre tamaño y propensión exportadora no siempre resulta significativa (Diamantopoulos e Inglis, 1988).

A pesar de que la investigación no es concluyente al determinar la magnitud y el sentido de la relación entre tamaño y propensión exportadora, la investigación apoya mayoritariamente el punto de vista normativo previamente referido, según el cual la actividad exportadora está concentrada en empresas de mediano y gran tamaño (Fernández y Nieto, 2002; Martín-Armario, Acedo y Martín-Ruiz, 2003; López, 2004; García-Canal, Guillén y Valdés-Llaneza, 2012). Esta misma afirmación se hace en el ámbito cooperativo. Concretamente, Fayos, Calderón y Mir (2011) afirman que la vinculación con los mercados exteriores de las cooperativas se realiza prioritariamente a través de la exportación debido, en demasiadas ocasiones, a la falta de dimensión. En síntesis, los argumentos previos permiten formular la hipótesis siguiente.

H4. Disponer de presupuesto de innovación en las empresas de Economía Social andaluzas, afecta el incremento de la propensión exportadora en los años 2002 y 2013.

Según Basile (2001) y Cassiman y Golovko (2011), la innovación podría ser un factor explicativo importante del resultado exportador y es que, cada vez tiene más aceptación en la literatura especializada el vínculo positivo y recíproco entre propensión exportadora e innovación (Chiva, Ghauri y Alegre, 2011; Kafouros, Buckley, Shapr y Wang, 2008).

Aunque los indicadores que miden la innovación empresarial pueden referirse a los recursos y capacidades, al proceso o a los resultados de innovación; el indicador más habitual, aunque imperfecto (Moreno y Rodríguez, 1998) es el presupuesto destinado a innovar.

H5. El uso de internet como canal comercial, favorece la propensión exportadora de las empresas de Economía Social andaluzas en los años 2002 y 2013.

En las últimas décadas, las Tecnologías de la Información y la Comunicación (TIC) han posibilitado el acceso a un nuevo canal de distribución - comercio electrónico-, que permite incrementar la actividad internacional. Según Izquierdo, Martínez y Jiménez (2010), multitud de empresas deciden ofrecer también sus productos o servicios a través de este canal, puesto que, además de eliminar las barreras geográficas, los beneficios del comercio electrónico son numerosos y sustanciosos.

Entre esos beneficios la literatura consultada resalta los siguientes: mayor control de las actividades de distribución, reducción de los costes de transacción (Strader y Shaw, 1997), incremento de la eficiencia en la ejecución de las actividades de la cadena de valor (Evans y Wurster, 1997), más facilidades para desarrollar la actividad exportadora (Houghton y Winklhofer, 2004) y garantía de un resultado exportador más activo (Alonso, 1994).

Según Ganotakis y Love (2009), el uso del comercio electrónico no influye en el impulso de entrada en los mercados de exportación, pero la extensión de su uso se asocia 
positivamente con el aumento de la intensidad de exportación. Es por los argumentos referidos que se propone la hipótesis.

El resultado del planteamiento y justificación de las hipótesis es el modelo conceptual que se presenta en el gráfico siguiente.

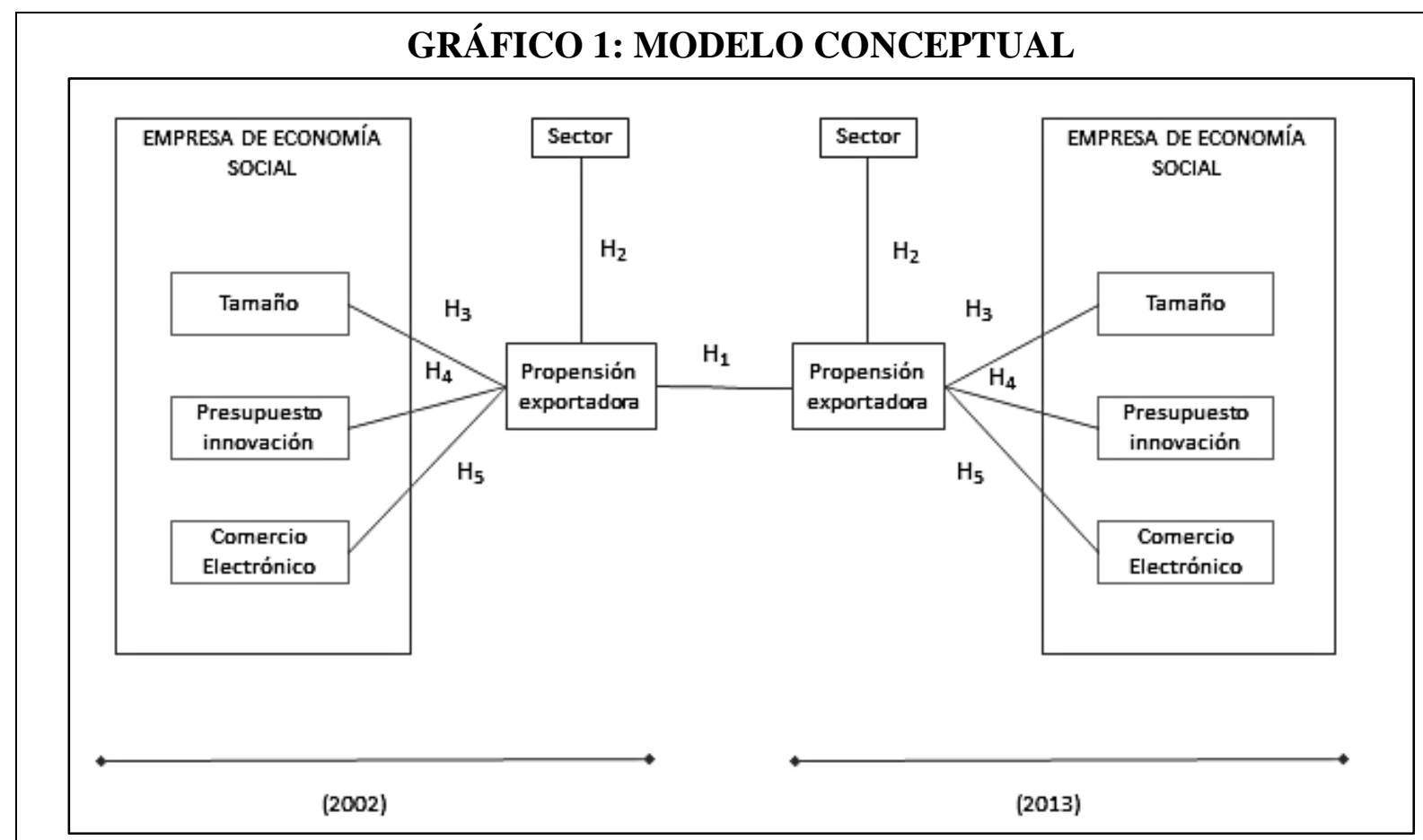

Fuente: Elaboración propia

\section{METODOLOGÍA}

Este apartado versa sobre el método de captación y tratamiento de datos y, en particular, contempla el detalle de las seis variables, la descripción de la población y la muestra, así como la enumeración de los métodos estadísticos empleados. Además de recoger la aportación teórica de la investigación a partir de la exposición de las variables determinadas, denominación y comprensión en base a su propia verificación en la literatura, es decir, la selección de las variables de control fue conforme a estudios previos de otros autores. Como así atesora el siguiente cuadro en el despliegue del tipo de variables.

Seguidamente, se acudió al tratamiento de una fuente primaria acopiando una serie de datos seleccionados del tejido empresarial protagonista con el objeto de abordar una retrospección. En consonancia, para medir las variables seleccionadas, se diseñó un cuestionario semiestructurado de 12 preguntas, testado por los grupos de investigación de la Universidad de Sevilla: SEJ301: PYMES, gestión y competitividad y SEJ230: Planificación y Análisis Económico. Para posteriormente, recopilar los datos necesarios de una muestra representativa del sector de Andalucía como queda estipulado en la ficha técnica.

\subsection{Descripción de la población y muestra}

Este análisis exigió iniciar la investigación delimitando un objeto material: las empresas - cooperativas y sociedades laborales- que integran el sistema de Economía Social andaluz. En este sentido, el Ministerio de Trabajo e Inmigración, cifró en 5.543 el número total de sociedades activas — cooperativas y sociedades laborales- en 2002 (Clemente, Díaz y 
Marcuello, 2008). Mientras que al cierre de 2013, este total ascendía a 7.026 empresas (CEPES-Andalucía, 2013).

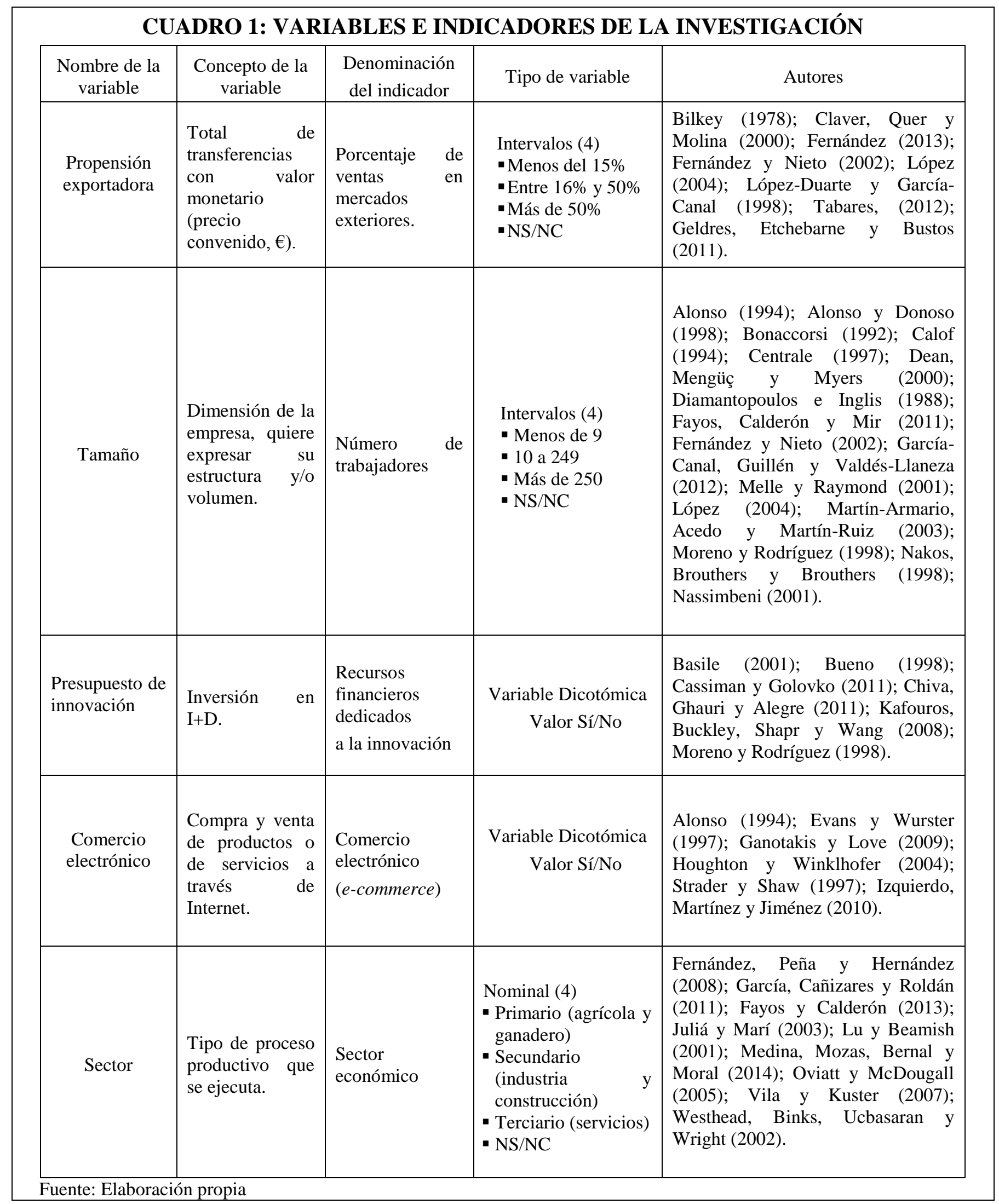


En la siguiente descripción técnica se incluyen los datos compilados del estudio, cuya recogida se realizó en 2003 y en 2014. Es importante señalar que se tratan universos distintos, si bien al inicio de la investigación partíamos de una fuente primaria en relación a la base de datos de las empresas, transcurrido el tiempo gran parte de la muestra de 2002 no se localizó. Por otra parte, se adquirió una limitación derivada de las fuentes secundarias al no revelar el total de empresas exportadoras de Economía Social de Andalucía, repercutiendo como desconocido en el estudio y llevando a instar la necesidad de bases de datos accesibles y actualizados. Frente a tal inexistencia, se optó por elaborar un directorio empresarial propio de empresas exportadoras localizables a partir de fuentes secundarias y CEPES-Andalucía. A ello, hay que añadir que 2.542 empresas andaluzas exportaban de forma regular en 2002 (Cámara de Comercio, 2003) y en 2013 respondían a un total de 3.920 (Extenda, 2014). Durante el proceso de encuestación se identificaron empresas nulas y no exportadoras. Los datos manejados, pues, fueron de carácter primario, específico, transversal y externo (inexistentes hasta el proceso de recogida de información propia del elemento muestral).

\begin{tabular}{|c|c|c|}
\hline \multicolumn{3}{|c|}{ CUADRO 2: FICHA TÉCNICA } \\
\hline Metodología & 2002 & 2013 \\
\hline Proceso metodológico & $\begin{array}{l}\text { Encuestas telefónicas, y en su mayoría } \\
\text { mediante una entrevista personal de una } \\
\text { duración aproximada de } 45 \text { minutos. }\end{array}$ & $\begin{array}{l}\text { Encuestas telefónicas, y en su mayoría } \\
\text { mediante una entrevista propia de una } \\
\text { duración aproximada de } 25 \text { minutos. }\end{array}$ \\
\hline Tipo de preguntas & Dicotómicas, nominales e intervalos & Dicotómicas, nominales e intervalos \\
\hline Universo poblacional & $\begin{array}{l}5.543 \text { empresas andaluzas de Economía } \\
\text { Social }\end{array}$ & $\begin{array}{l}7.026 \text { empresas andaluzas de Economía } \\
\text { Social }\end{array}$ \\
\hline Muestra obtenida & $\begin{array}{l}514 \text { empresas andaluzas de Economía } \\
\text { Social }\end{array}$ & $\begin{array}{l}121 \text { empresas andaluzas de Economía } \\
\text { Social }\end{array}$ \\
\hline Forma de contacto & Correo electrónico y teléfono & Correo electrónico y teléfono \\
\hline Método de muestreo & $\begin{array}{l}\text { Muestreo aleatorio simple para } \\
\text { proporciones con un nivel de confianza } \\
\text { del } 95 \% \text { y con el supuesto de máxima } \\
\text { indeterminación }(\mathrm{p}=\mathrm{q}=0,5) \text {. }\end{array}$ & $\begin{array}{l}\text { Muestreo aleatorio simple para } \\
\text { proporciones con un nivel de confianza del } \\
95 \% \text { y con el supuesto de máxima } \\
\text { indeterminación }(\mathrm{p}=\mathrm{q}=0,5) \text {. }\end{array}$ \\
\hline Error & $\pm 4,11 \%$ & $\pm 8,83 \%$ \\
\hline Fecha de encuestación & Enero a junio de 2003 & Enero a junio de 2014 \\
\hline
\end{tabular}

Finalmente, cabe señalar que el proceso metodológico presenta una variación específica en el segundo momento -2014- derivado del descenso poblacional y la falta de recursos económicos como consecuencia de la crisis, entre otras razones.

\subsection{Selección de los métodos estadísticos}

La recogida de datos se realiza a través de un cuestionario estructurado de naturaleza personal durante los años 2003 y 2014. Asimismo, el empleo del SPSS/PC (V23) posibilita la generación de la información necesaria.

La extracción de los elementos muestrales, de dos grupos (514/121 empresas), se realiza mediante un procedimiento de muestreo aleatorio simple, fundamentado en el azar y aplicado 
mediante tablas de números aleatorios. Por último, debemos señalar que procedimos a eliminar del análisis las respuestas desconocidas de ambos grupos.

Para contrastar las hipótesis que se formulan, se eligieron el método estadístico descriptivo e inferencias, fundamentado en: frecuencias, tablas de contingencia, contrastes de hipótesis para comparar proporciones en base a la prueba $z$ y la correlación bivariada usando el coeficiente de Spearman.

Una vez tratados los datos y lograda la información cuantitativa, los autores generan conocimiento útil para que, al menos potencialmente, los gestores y órganos directivos de las cooperativas y sociedades laborales, especialmente las andaluzas, orienten sus políticas exportadoras y para que el personal investigador interesado amplíe su conocimiento sobre el sector exportador de la Economía Social de la región.

\section{RESULTADOS}

En este apartado se comenta el producto de la investigación. De forma que, en primer lugar, se presentan las derivaciones del análisis de cada una de las variables implicadas para cada año (2002 y 2013) y, en segundo lugar, se expone el contraste de hipótesis para los años considerados.

\subsection{Análisis descriptivo de las variables analizadas}

Al comparar el porcentaje de empresas para cada intervalo de facturación en el exterior (en relación a la facturación global), se registra: una disminución del 34,98 puntos porcentuales en el intervalo inferior al 15 por 100, un aumento del 14,84 en el tramo 16-50 por $100 \mathrm{y}$ un aumento del 20,15 en el intervalo superior al 50 por 100 .

\section{GRÁFICO 2: PROPENSIÓN EXPORTADORA DE LA ECONOMÍA SOCIAL}

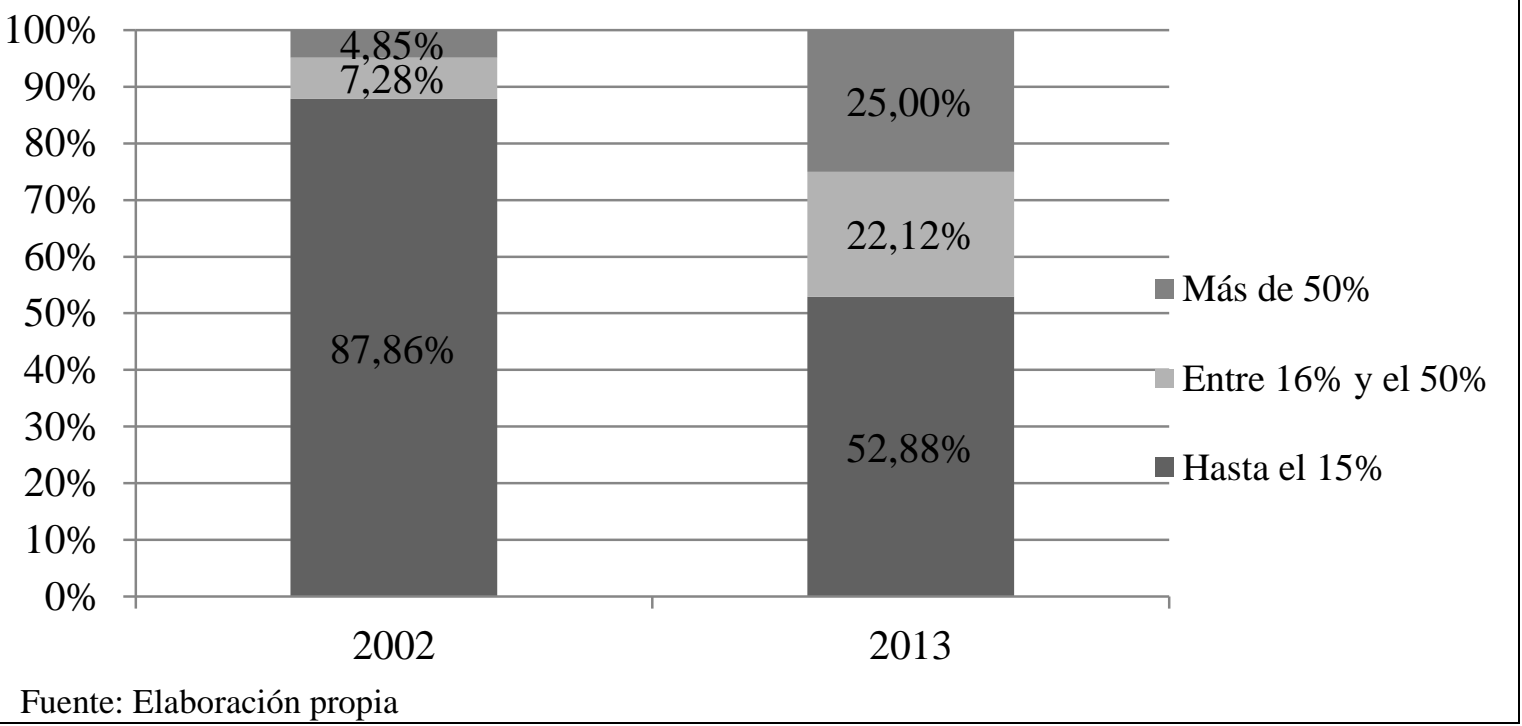

En lo referente al tamaño empresarial, se produce un ascenso de dimensión destacando las empresas de más de 250 trabajadores, cuyo aumento reconoce una tasa de variación del 5,8 por 100 entre 2002 y 2013. Se observa la adquisición de dimensión en las empresas pymes, entre 10 y 249 trabajadores, mientras que, se reduce el peso de las MYPES. Así, en 
2002 las empresas de menos de 10 trabajadores representaban al 76,28 por 100 del tejido empresarial exportador, y en 2013 se produce un descenso hasta el 47,11 por 100. De esta manera, se manifiesta que las empresas con actividad exterior de Economía Social son MYPES y PYMES, a partir de un nivel de significación 0,05 en relación al tamaño de las empresas sobre los intervalos estudiados.

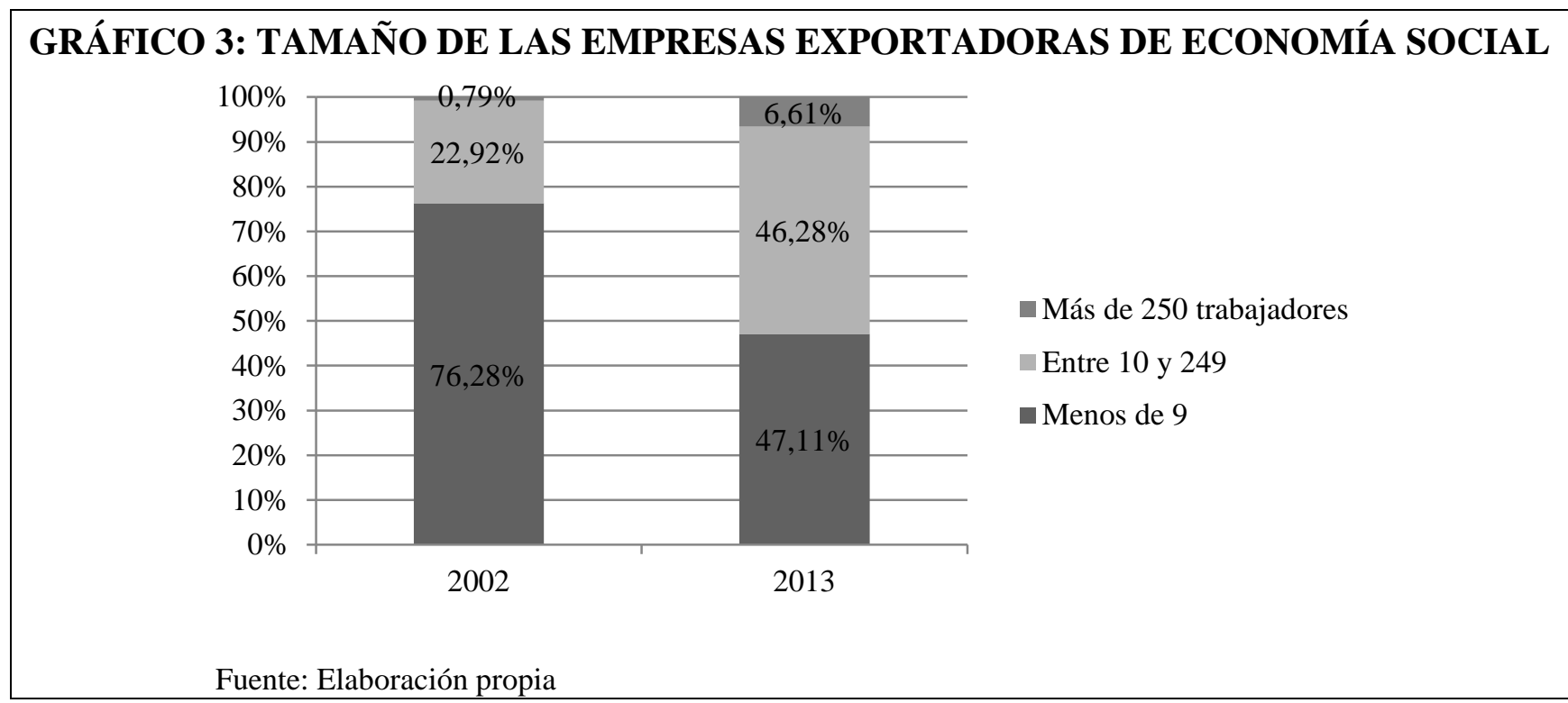

Las empresas de Economía Social disponen de presupuesto a innovación, se observa que en 2002 más del 60 por 100 invertía en innovación, mientras que en 2013 lo hacía el 76,86 por 100, comprobándose con ello que los recursos destinados a innovar son una constante empresarial.

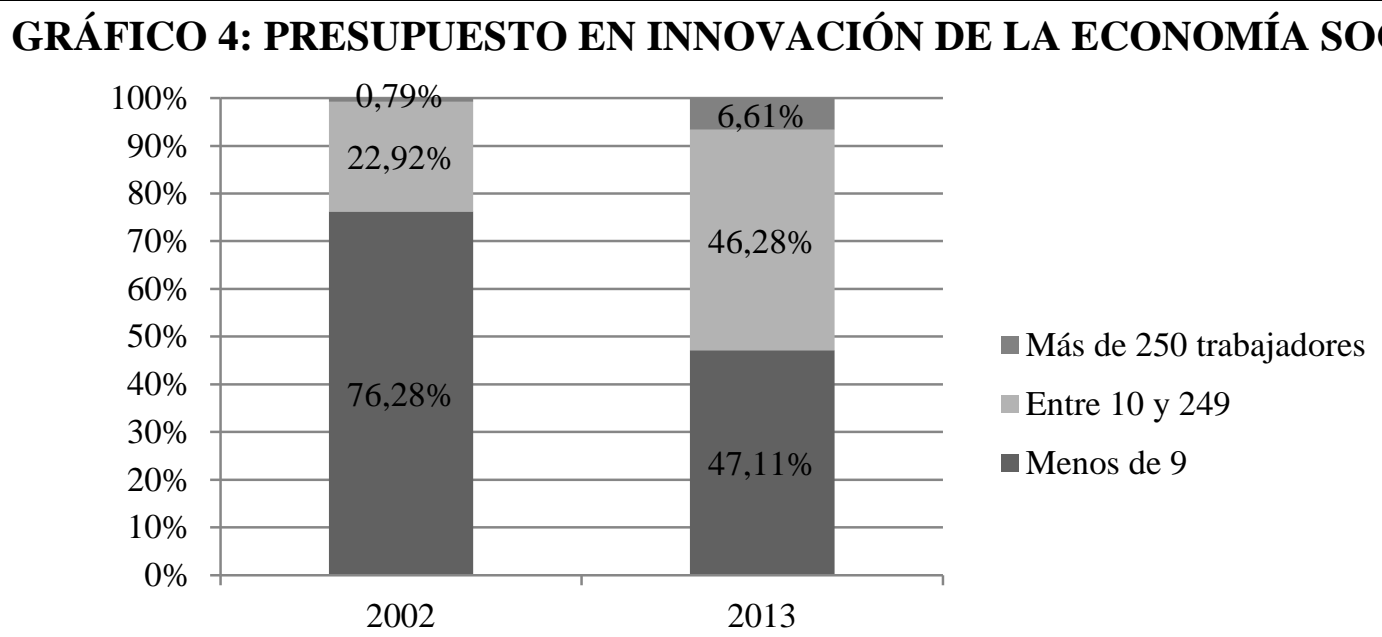

Fuente: Elaboración propia

Hay que sumar, una mínima variación del comercio electrónico como canal de distribución, de manera que, el mismo no adquiere protagonismo en el tiempo. Según los 
datos obtenidos, las empresas de Economía Social no apuestan por el comercio electrónico, indicador que lleva a reflexionar sobre la orientación local de la Economía Social andaluza en detrimento de la orientación exterior. Así, puede que se halle en un punto inicial del proceso, quedándole por avanzar en la internacionalización.

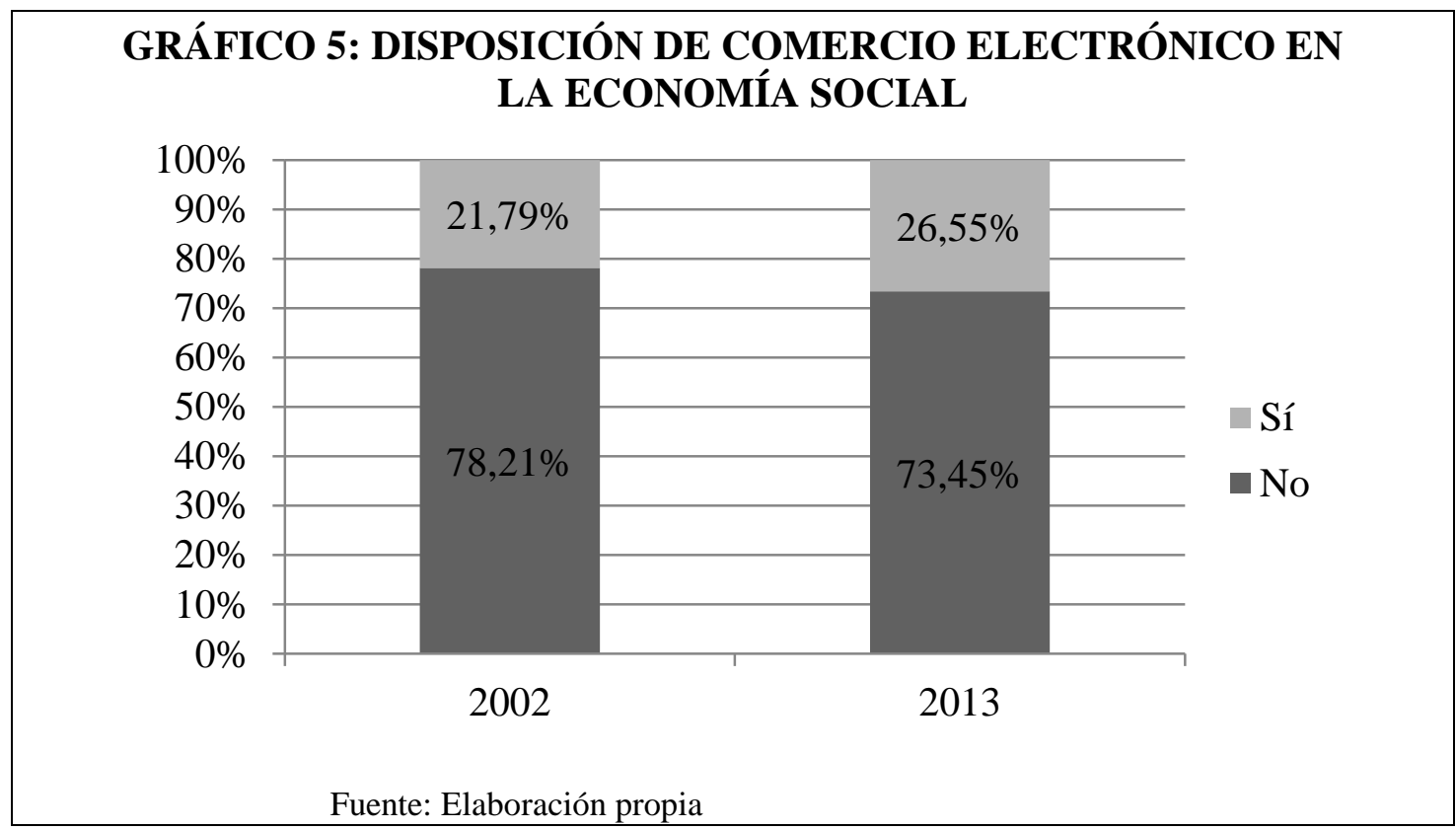

Las empresas de Economía Social en 2002, mayoritariamente, pertenecen al sector terciario (46,98 por 100). Al analizar su comportamiento en el tiempo, se comprueba que se ha producido un declive a favor de las empresas con actividad exterior en el sector secundario. Es decir, el sector industrial incrementa su dinamismo, llegando a ocupar en 2013 más del 50 por 100 de la actividad económica exterior de Economía Social. Destacar su aumento con el registro de una tasa de variación más elevada del 30 por 100 entre 2002 y 2013, manifestando, a su vez, la invalidez de la afirmación arraigada sobre la carencia de tejido industrial en la región andaluza.

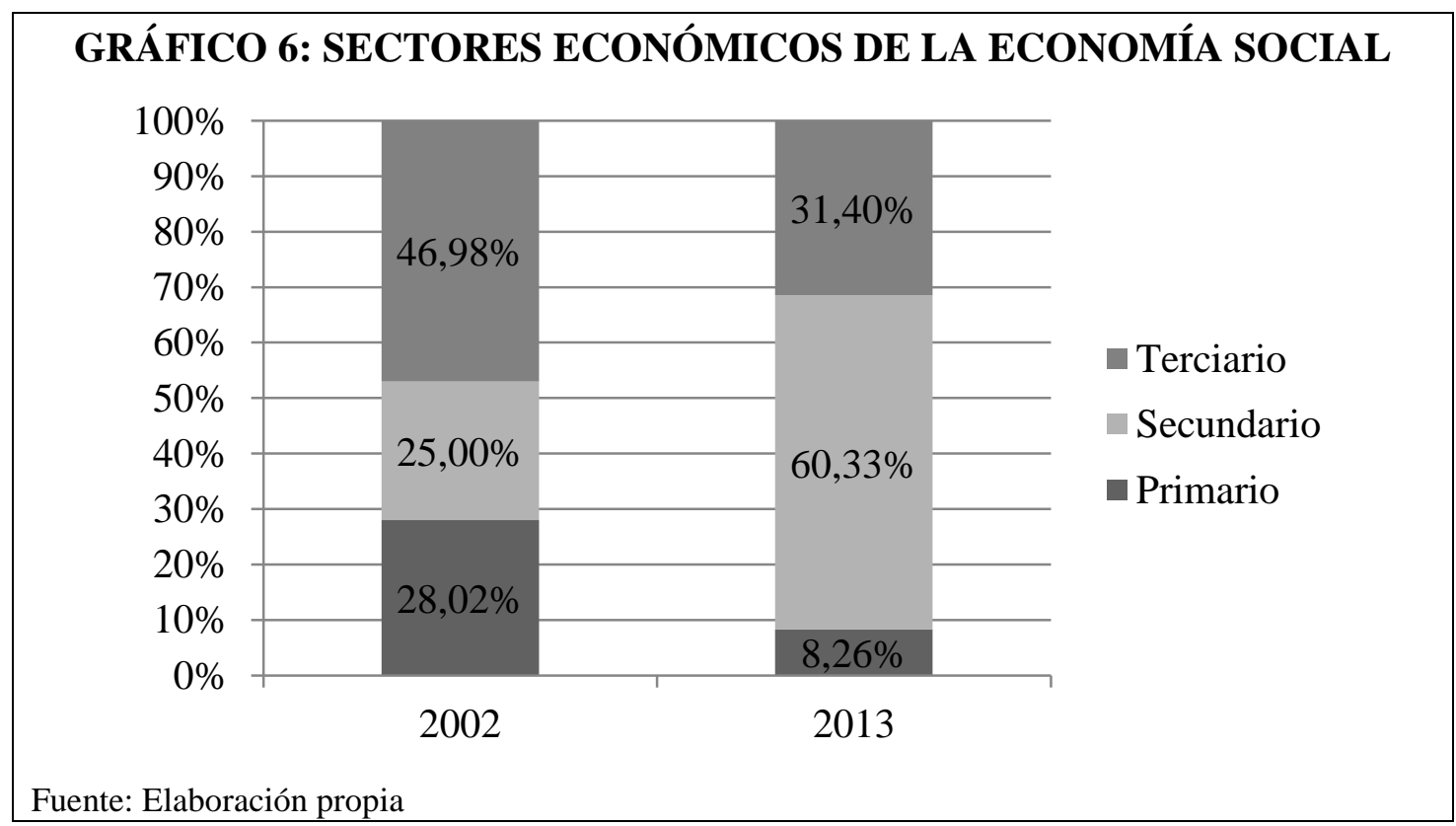


Al mismo tiempo que se evidencia la caída del sector terciario a favor del sector secundario, acontece un descenso temporal del sector primario, singularidad cuando hay numerosos reconocimientos al sector agroalimentario exterior, unas revelaciones con nivel de significación 0,05 .

\subsection{Análisis de los resultados relativos a las hipótesis}

H1. La propensión exportadora de las empresas de Economía Social andaluzas aumenta en el horizonte temporal $2002-2013$.

Se observa un aumento revelador (con nivel de significación del 0,05 por 100) de la propensión exportadora, puesto que, al comparar el porcentaje de empresas para cada intervalo de facturación en el exterior sobre la facturación global, incrementan su peso los intervalos $16-50$ por 100 y superior al 50 por 100. Dos tramos que ascienden en contraposición del tramo inferior al 15 por 100 , es decir, más de un 60 por 100 del porcentaje de facturación en el exterior escala variaciones.

H2. El sector agrario de la Economía Social andaluza presenta la mayor propensión exportadora, en los años 2002 y 2013.

En relación a la hipótesis $\mathrm{H}_{2}$ concluimos las evidencias que se detallan a continuación para el año 2002. Primeramente, la propensión exportadora de las empresas del sector primario se distribuye de acuerdo con los siguientes porcentajes: el 72,90 por 100 factura hasta el 15 por 100 de su facturación global en los mercados exteriores, el 15,89 por 100 registra entre el 16 y el 50 por 100 , el 11,21 por 100 liquida más del 50 por 100 de su volumen de ventas en el exterior. Por su parte, la propensión exportadora de las empresas de los sectores secundario y terciario es inferior, en la mayoría de las empresas, al 15 por 100 de la facturación global.

Se prueba una correlación negativa -débil- significativa (nivel 0,01) entre las variables sector económico y porcentaje de facturación en el exterior, es decir, existe una relación entre el sector primario y una mayor propensión exportadora. En el mismo sentido, se pone de manifiesto que los resultados obtenidos en los dos intervalos de facturación de mayor rango son significativamente superiores en el sector primario. Tanto es así que, en 2013 la propensión exportadora de las empresas del sector primario se concentra en facturar más del 50 por 100 de su volumen de ventas en el exterior (60 por 100). Sector que discrepa del resto de sectores que presentan una distribución cambiante y expansiva en los intervalos registrados.

Las empresas del sector primario se distribuyen de acuerdo con los siguientes porcentajes: un 20 por 100 registra hasta el 15 por 100 de su facturación global en los mercados exteriores, el 20 por 100 factura entre el 16 y el 50 por 100 y el 60 por 100 liquida más del 50 por 100 de su volumen de ventas en el exterior. Por su parte, la propensión exportadora de las empresas de los sectores secundario y terciario es inferior en la mayoría de las empresas al 15 por 100 de la facturación global, resultando una constante temporal.

H3. El tamaño de las empresas de Economía Social andaluzas influye en su propensión exportadora en los años 2002 y 2013.

En relación a la hipótesis $\mathrm{H}_{3}$ concluimos las evidencias que se detallan a continuación para el año 2002, pues la propensión exportadora para las MYPES, PYMES y empresas de más de 250 trabajadores la marca una facturación hasta el 15 por 100 en el exterior. Es decir, se distribuye de acuerdo con los siguientes porcentajes: 92,28 por 100 MYPES, 73,12 por 100 PYMES y el 75 por 100 empresas de más de 250 trabajadores facturan hasta el 15 por 100 en el exterior. Asimismo, se observa que el porcentaje de ventas hasta el 15 por 100 es 
significativamente superior en las empresas de menos 9 trabajadores respecto a las que tienen entren 10 y 249 empleados, realzando la ocupación de las MYPES en el sector estudiado. Además, los dos siguientes intervalos de porcentaje de facturación son significativamente inferiores en las empresas de menos de 9 trabajadores respecto a las PYMES. Registrando así, una congregación del tejido MYPE con una facturación en el exterior hasta el 15 por 100 en 2002 .

\section{GRÁFICO 7: PROPENSIÓN EXPORTADORA DE LA ECONOMÍA SOCIAL POR SECTORES}

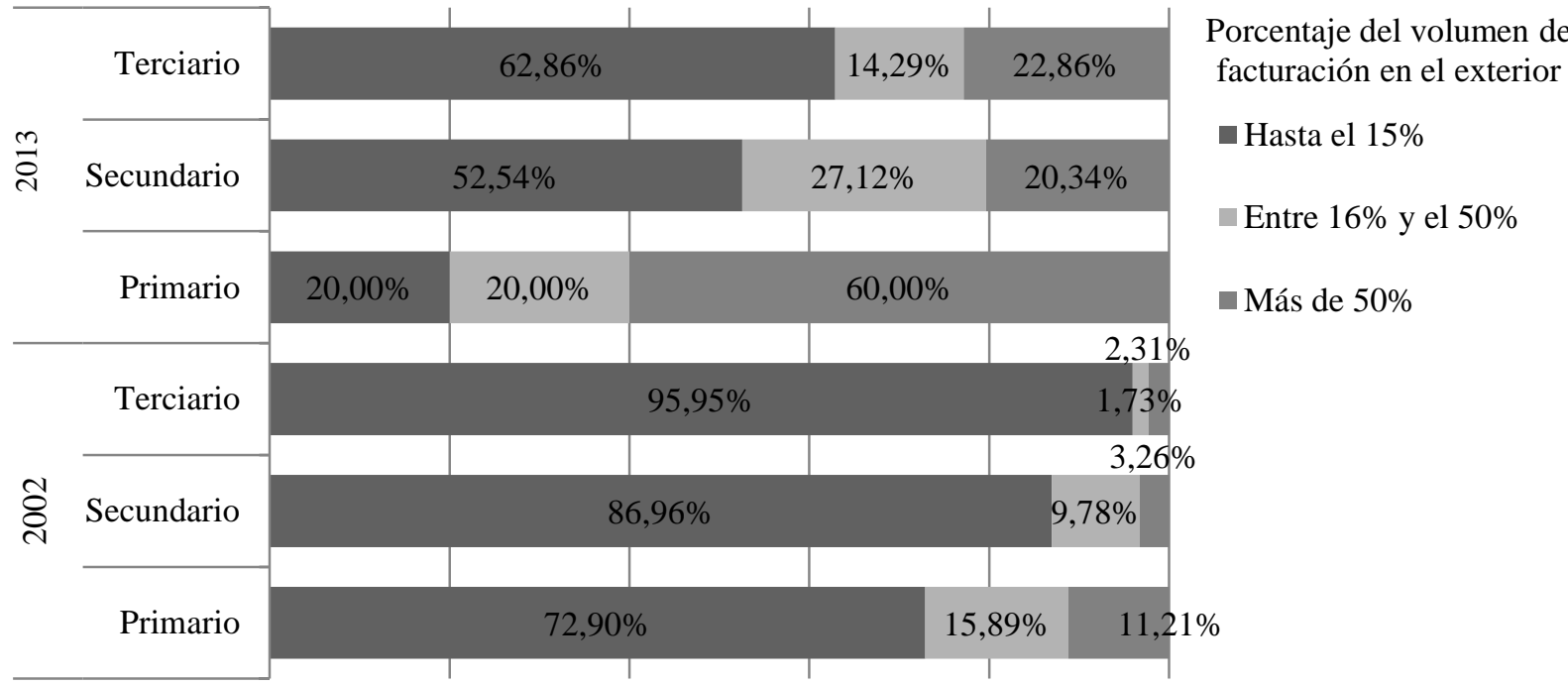

Fuente: Elaboración propia

Llegado 2013, se produce una propagación en los intervalos estudiados. De manera que, adquiere representación el porcentaje de empresas que factura en el exterior más del 50 por 100. Por otra parte, aunque el análisis descriptivo refleja desigualdades entre los diferentes tamaños de empresas, los contrastes de hipótesis solo hallaron diferencias específicas en las MYPES (menos de 9 trabajadores), pues obtienen un resultado significativamente superior en el porcentaje de ventas hasta el 15 por 100 respecto a las empresas de más de 250 empleados.

Por consiguiente, existe correlación significativa - nivel 0,01- entre las variables tamaño y porcentaje de facturación al exterior. La relación entre ambas variables es positiva, esto quiere decir que, cuando una aumenta la otra aumenta también. Es oportuno detallar que esta relación no es fuerte (relación débil) ya que la correlación de Spearman está próxima a 0. Dicho de otro modo, a mayor intervalo en el tamaño de empresas, mayor será la propensión exportadora. Una vinculación afianzada en el cruce de ambas variables y contrastes de hipótesis.

H4. Disponer de presupuesto de innovación en las empresas de Economía Social andaluzas, afecta el incremento de la propensión exportadora en los años 2002 y 2013.

En relación a la hipótesis $\mathrm{H}_{4}$ concluimos las evidencias que se detallan a continuación para el año 2002. Así, la propensión exportadora de las empresas que destinan presupuesto a innovar es superior, el 6,2 por 100 factura más del 50 por 100 en el exterior. Igualmente, las empresas que sí innovan muestran un resultado significativamente superior en el intervalo del 
16 al 50 por 100 de ventas en el exterior. En cambio, las empresas que no innovan alcanzan un porcentaje superior y representativo en el intervalo de ventas exterior hasta el 15 por 100 .

Para 2013, no se consiguen diferencias significativas entre aquellas empresas que innovan y las que no, pues los hallazgos son semejantes. Bien es cierto, que se puede precisar la decisión de invertir en innovación, pues se distribuye de acuerdo con los siguientes porcentajes: 54,35 por 100 registra hasta el 15 por $100,20,65$ por 100 factura entre el 16 y el 50 por 100 , y el 25 por 100 más del 50 por 100 en el exterior.

En esta concordancia, las comprobaciones no permiten hallar correlaciones, por eso la relación de ambas variables no puede medirse. Si se utiliza el análisis descriptivo y contrastes de hipótesis para observar si hay diferencias significativas en el porcentaje de facturación en el exterior entre aquellas empresas con y sin innovación, se concluye la inexistente vinculación entre el presupuesto de innovación y la propensión exportadora.

\section{GRÁFICO 8: PROPENSIÓN EXPORTADORA DE LA ECONOMÍA SOCIAL POR TAMAÑO}

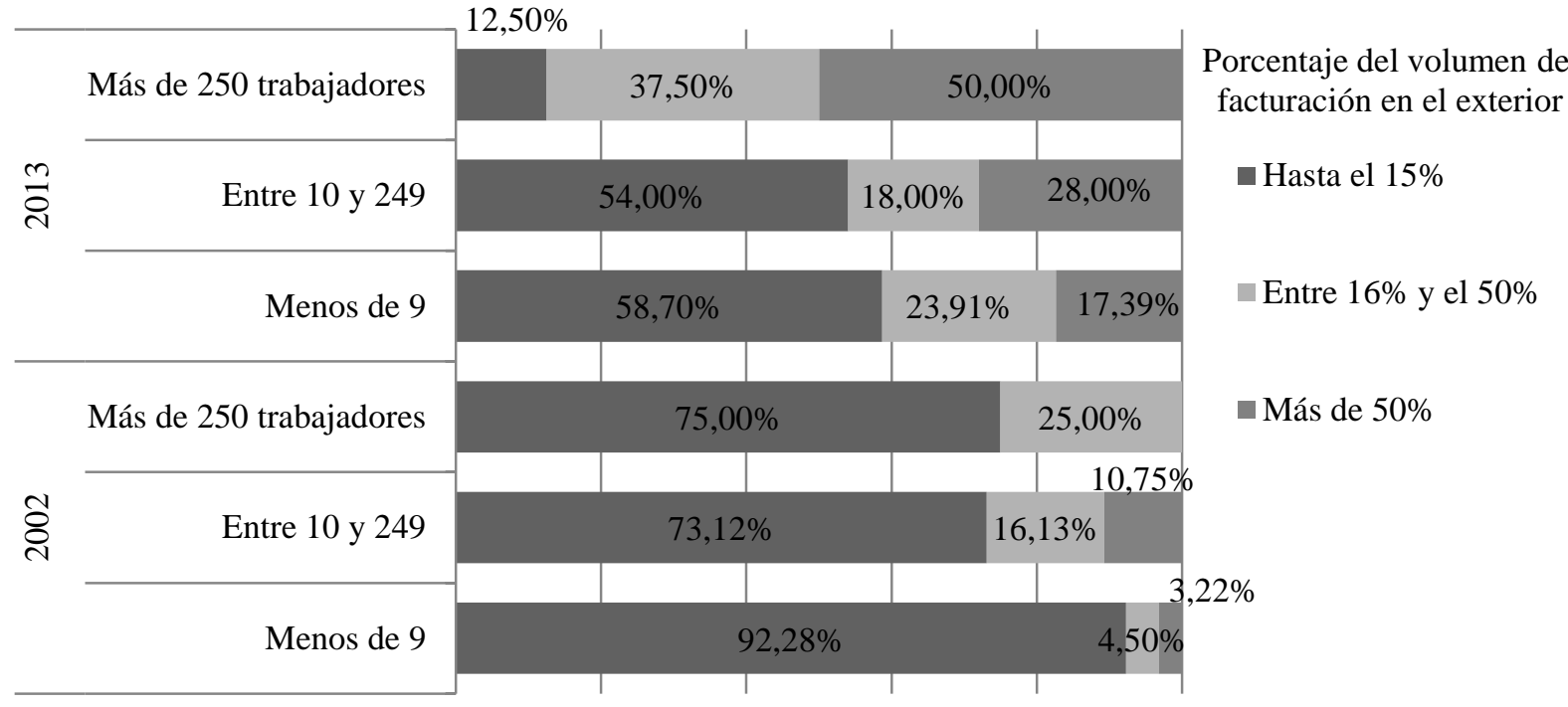

Fuente: Elaboración propia

H5. El uso de internet como canal comercial, favorece la propensión exportadora de las empresas de Economía Social andaluzas en los años 2002 y 2013.

En relación a la hipótesis $\mathrm{H}_{5}$ concluimos que las empresas exportadoras de Economía Social no tienden a utilizar Internet como canal comercial. En los años estudiados solo 4,76 puntos porcentuales ha mejorado la disposición de comercio electrónico, claro exponencial de la brecha digital del sector.

En particular, las comprobaciones no permiten hallar correlaciones, por eso la relación de ambas variables no puede medirse. Si se utiliza el análisis descriptivo y contrastes de hipótesis para observar si hay diferencias significativas en el porcentaje de facturación en el exterior entre aquellas empresas con y sin comercio electrónico, se concluye la inexistente vinculación entre el comercio electrónico y la propensión exportadora.

Con carácter general, se concluye que las empresas de Economía Social andaluzas presentan, en el periodo de tiempo 2002 y 2013, un incremento de su propensión exportadora, que está conectado a la evolución del factor interno, tamaño, y del factor externo, sector económico y/o especialización. 


\section{GRÁFICO 9: PROPENSIÓN EXPORTADORA DE LA ECONOMÍA SOCIAL CON PRESUPUESTO DE INNOVACIÓN}

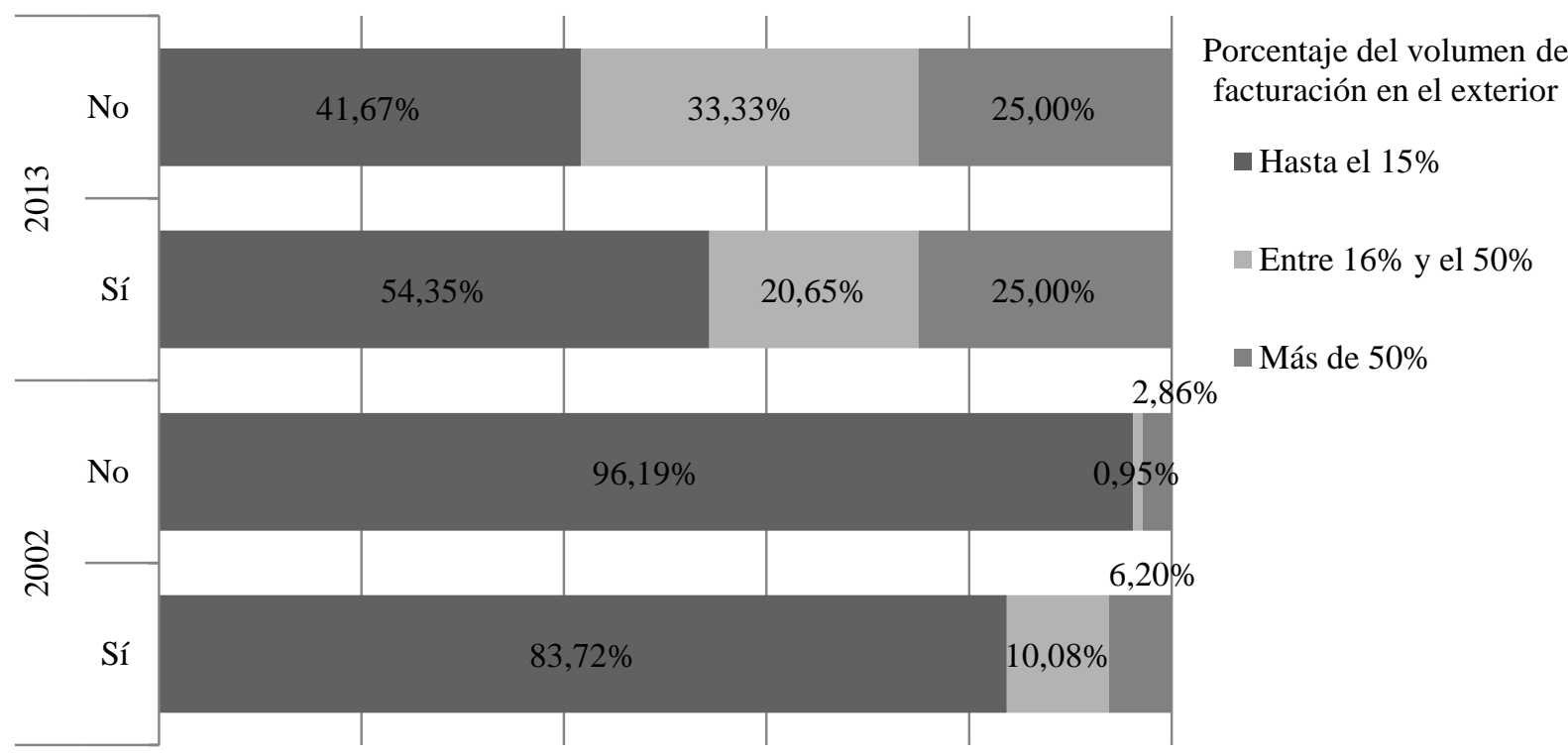

Fuente: Elaboración propia

\section{CONCLUSIONES}

Este apartado versa sobre las conclusiones, implicaciones, limitaciones y futuras líneas de investigación.

Las conclusiones empíricas son diversas. Con carácter general y atendiendo al horizonte temporal 2002 y 2013, el análisis descriptivo de las empresas exportadoras de Economía Social andaluzas muestra un incremento en el volumen de la facturación en el exterior, la dimensión empresarial, el número de las que cuentan con presupuesto de innovación, la utilización del comercio electrónico y el peso del sector secundario. Se puede señalar que la empresa exportadora andaluza de Economía Social, principalmente, es una MYPE que vende en el exterior hasta el 15 por 100 de su facturación, opera en el sector secundario y/o terciario, destina presupuesto a innovar y no utiliza e-commerce. Inmediatamente, se trata cada una de estas variables.

En primer lugar, aumenta el número de empresas con volumen de ventas en el exterior en los intervalos entre el 16 y el 50 por 100 y más del 50 por 100. Acentuación manifiesta, pues más del 40 por 100 se hallan en estos intervalos en 2013, asimismo, se descubre una mayoría empresarial debajo del 15 por 100 de ventas en el exterior en ambos momentos estudiados. Cierto es que se trata de una variable determinante que condiciona la estrategia de expansión internacional y ejerce influencia en el resultado empresarial (Bobillo, LópezIturriaga y Tejerina-Gaite, 2010).

En segundo lugar, se comprueba que desde 2002 ha aumentado el peso de las que cuentan con mayor tamaño en relación a su propensión exportadora. Se observa cómo entre 2002 y 2013 ha acentuado el porcentaje de PYMES mientras que las MYPES han disminuido, destacando el incremento de empresas con más de 250 trabajadores. Unas comprobaciones reveladoras para un sector compuesto en su mayoría por PYMES y que, a su vez, confirman 
que es necesario tener en cuenta la dimensión empresarial como variable que influye en la actividad exterior.

Si se delibera sobre la determinación de la variable tamaño, puede que no sea un factor íntegramente concluyente del proceso de internacionalización, pero sí lo condiciona (Fayos, Calderón y Mir, 2011). Así, lo señala nuestra evidencia empírica, en la que las MYPES descienden y las PYMES -entre 10 y 249 trabajadores- ascienden. Refutación en sintonía con otras autorías, pues se hallan diferencias en la productividad y tamaño de las empresas con actividad exterior. Cierto es, como señala Hollenstein (2005), que el tamaño influye en la actividad internacional solamente cuando la organización es aún pequeña dado que este tipo empresarial se enfrentan a ciertas limitaciones físicas y financieras para lograr la internacionalización, indicador que se cumple en el sector andaluz de Economía Social.

En tercer lugar, se indica que el presupuesto de innovación no determina la variación de la propensión exportadora de las entidades de Economía Social. Específicamente, las empresas destinan más recursos a innovar y como efecto favorece su desarrollo exterior, pero sin resultar significativo. La constatación se observa como un progreso, pues en 2002 un 63,8 por 100 invertía en innovación, y el 76,8 por 100 en 2013. Sobre lo que se puede puntualizar que, el comportamiento exportador es una manifestación de la actitud innovadora (Bueno, 1998). Por otra parte, se detecta un ascenso no demostrativo del comercio electrónico como canal de distribución.

Al mismo tiempo, se ha evidenciado que el sector económico influye en su propensión exportadora, pues los sectores con mayor dinamismo exterior son el primario y el terciario. Cierto es que, por ocupación el primario pierde peso, mientras que el secundario lo gana, cambios que pueden derivar de la especialización sectorial. En este sentido, se atiende a los trabajos de Canals y Termes (1991) y Bartlett y Ghoshal (1991), cuando aluden al éxito de las operaciones internacionales determinado por: la adaptación al sector y la transferencia de tecnología, entre otros factores.

Registrado ello, esta investigación demuestra que la propensión exportadora de las empresas de Economía Social andaluzas aumenta en el horizonte temporal 2002-2013; y que el sector agrario y la dimensión empresarial presentan mayor propensión exportadora. Además, se expone la inexistente relación anexa entre el presupuesto de innovación y el comercio electrónico (e-commerce) con la propensión exportadora en los citados años, es decir, no se confirman las hipótesis cuatro y cinco. Hecho último que puede acontecer como efecto de la falta de homogeneidad en el tamaño de la muestra estudiada y/o en la medición. Sabido es que la innovación puede medirse por múltiples indicadores y que el e-commerce, por su parte, presenta escaso o inusual tratamiento empírico, donde se halla una necesidad de mejora en la medición, e incidimos en un perfeccionamiento propio.

En consecuencia, las hipótesis de la investigación se sostienen, se confirman tres de las cinco planteadas. Considerando que las empresas de Economía Social andaluzas presentan, en el periodo de tiempo 2002 y 2013, un incremento de su propensión exportadora, conectado a la evolución del factor interno, tamaño, y del factor externo, sector económico. Definitivamente, con estas conclusiones se trata la propensión exportadora en la Economía Social andaluza retando la ausencia de estudios similares y aportando conocimientos.

Se genera conocimientos a partir del tratamiento de la propensión exportadora en un sector empírico preciso con refutación en la literatura. A nivel teórico, esta investigación se adhiere a anteriores demostraciones, del mismo modo, incluye la variable e-commerce. En otras palabras, se puede especificar que la principal conclusión teórica es que se generan nuevas evidencias científicas sobre los tópicos, propensión exportadora y cooperativas, en un 
ámbito en el que la literatura presenta importantes deficiencias como es el sistema andaluz de empresas de Economía Social.

Las implicaciones de la investigación involucran a dos principales destinatarios, los directivos del tejido empresarial y la Administración Pública regional. Al igual que se ha distinguido entre factores internos y externos, en relación a las decisiones empresariales en la mayoría de los factores se combinan motivos internos y externos, es decir, es un multiestímulo el que conduce la decisión de exportar y, por tanto, todos los motivos suman, incluido los científicos. La Administración Pública ha de esforzarse en disponer un marco institucional que trabaje por mejorar continuamente el entorno en el que se mueven las empresas.

En relación a los hallazgos, se sugiere incrementar el volumen de ventas exteriores, la dimensión empresarial y el presupuesto destinado a la innovación. Conviene, por tanto, seguir invirtiendo en recursos para la creación de activos que sostengan la actividad exportadora de las empresas. De modo similar, las empresas de Economía Social han de crecer o se dificultará la supervivencia en un mercado altamente competitivo, aunque hay numerosas autorías que señalan la inexistente relación lineal entre la intensidad exportadora y el tamaño empresarial (González, 1999).

En todo caso, el poder contar con más empresas de Economía Social y con más empresas exportadoras regulares es una condición necesaria. Tal como ha demostrado el sector exterior andaluz en los últimos años, solo aumentando la base empresarial se puede optimizar las estrategias internacionales, fraguar conocimientos específicos e impulsar resultados eficientes. Esto último, tal como indica el vigente Plan Estratégico de Internacionalización de la Economía Andaluza 2014-2020, que prevé incrementar el número de empresas exportadoras con el objetivo de situar a las exportaciones alrededor del 20 por 100 del PIB andaluz.

Por otra parte, las limitaciones de la investigación son heterogéneas. Por un lado están las limitaciones teóricas, halladas en dos líneas. Primeramente, si bien se plantea un modelo conceptual con parsimonia, las características pueden ser más precisas en base al número de variables e importancia. Seguidamente, están las reticencias que guardan relación con el rigor de la propensión exportadora, es decir, con la medición. La propensión exportadora ha sido medida a partir de factores internos y externos, definido cada factor con un indicador y siendo excluidos otros posibles. En aras de los resultados de la variable e-commerce, la misma resulta una limitación importante cuya medición ha sido errónea. Sin embargo, las limitaciones empíricas están ocasionadas por la disparidad del tamaño de la muestra, por la acotación geográfica, temporal y económica, así como por el método de captación de datos.

Las limitaciones confinan dificultades, así pues ampliar el tamaño del modelo conceptual conlleva aumentar el número de variables consideradas y la literatura que la soporta. Mejorar el rigor y/o medición de la propensión exportadora, contempla: una desagregación sectorial, definir la I+D a partir de las actividades y los tipos de innovación, contar con otros indicadores de la dimensión empresarial y restructurar la medición de la variable e-commerce. Puntualizar que, hasta el momento, esta última suele tratarse por la literatura en base a su incidencia en los resultados. Por otro lado, al incrementar los métodos de captación de datos, se le suma rediseñar el límite geográfico y temporal.

Finalmente, se trabaja en un estudio longitudinal pormenorizado (Fernández, Peña y Hernández, 2008) con características diferentes y temporalidades más frecuentes que permita detallar el crecimiento exportador de la Economía Social de Andalucía. 


\section{BIBLIOGRAFÍA}

Aaby, N. E. y Slater, S. F. (1989): "Management influences on export performance: a review of the empirical literature 1978-1988", International Marketing Review, 6 (4).

Alonso, J. A. y Donoso, V. (1998): Competir en el exterior. La empresa española y los mercados internacionales, Ed. ICEX, Madrid.

Alonso, J. A. (1994): "El comportament exportador de l'empresa espanyola: aplicació del mètode LISREL", Revista Económica de Cataluña, 26, 52-64.

Arias, A. (2004): "La Internacionalización de las empresas de la Comunidad Autónoma del País Vasco en el Periodo 1999-2001", Tesis Doctoral - Universidad de Deusto, España.

Barney, J. (1991): "Firm resources and sustained competitive advantage", Journal of Management, 17(1), 99-120.

Bartlett, C. A. y Ghoshal, S. (1991): "What is a global manager?" Harvard Business Review, 70(5), 124-132.

Basile, R. (2001): "Export behaviour of Italian manufacturing firms over the nineties: the role of innovation", Research Policy, 30, 1185-1201.

Berthou, A. y Vicard, V. (2013): "Firms' export dynamics: experience vs. size", recuperado de https://www.central.banktunnel.eu/pub/pdf/scpwps/ecbwp1616.pdf.

Bilkey, W. J. (1978): "An Attempted Integration of the Literature on the Export Behaviour of Firms", Journal of International Business Studies, 9(1) 1, 33-46.

Bobillo, A. M., López-Iturriaga, F. y Tejerina-Gaite, F. (2010): "Firm propensity and international diversification: The internal and external competitive advantages", International Business Review, 19 (6), 607-618.

Bonaccorsi, A. (1992): "On the relationship between firm size and export intensity", Journal of International Business Studies, 605-635.

Bueno, J.C. (1998): "El nivel de internacionalización de las empresas españolas con filiales en el exterior", Investigaciones europeas de dirección y economía de la empresa, 4 (2), 91-108.

Buesa, M. y Molero, J. (1998): Economía industrial de España: organización, tecnología e internacionalización, Madrid, Civitas.

Calof, J.C. (1994): "The Relationship between Firm Size and Export Behaviour Revisated", Journal of International Business Studies, 25 (2), 367-387.

Cámara de Comercio (2003): Las empresas exportadoras e importadoras en España y en las Comunidades Autónomas, recuperado de http://www.camaragranada.org/descargas/laempresa-exportadora-e-importadora-espanola-113doc.pdf.

Canals, J. y Termes, R. (1991): Competitividad internacional y estrategia de la empresa, Ariel.

Cassiman, B. y Golovko, E. (2011): "Innovation and internationalization through exports", Journal of International Business Studies, 42, 1-20

Centrale, M. (1997): “Indagine sulle imprese manifatturiere", Sesto rapporto sull'industria italiana e sulla política industriale, Ministero dell'Industria e Mediocredito Centrale, Il Sole, 24.

CEPES-Andalucía (2013): Informe Estadístico de la Economía Social Andaluza $4^{\circ}$ Cuatrimestre, Central de Estadísticas de la Economía Social de CEPES-Andalucía.

CEPES-Andalucía (2015): Recuperado de http://andaluciaeconomica.com/portada/no-277/ 
Chiva, R., Ghauri, P. y Alegre, J. (2011): "Innovating, learning and internationalizing: a mutual causality model”, Actas del Congreso Internacional EURAM, Tallin, Estonia.

Claver, E., Quer, D. y Molina, J. F. (2000): "La adaptación de la empresa a las presiones competitivas en el ámbito internacional: una aportación empírica”, Economía industrial, 333, 57-74.

Clemente, J., Díaz, M. y Marcuello, C. (2008): "Estudio sobre las cooperativas y sociedades laborales en España: creación de empleo y contribución al desarrollo económico", Dirección general de la Economía Social, del trabajo autónomo y del Fondo Social Europeo, Ministerio de Trabajo e Inmigración, Código F08348, Universidad de Zaragoza.

Correa-López, M. y Doménech, R. (2012): "La internacionalización de las empresas españolas", 1229, BBVA Bank, Economic Research Department.

Cortés, F.J. (2001): "La orientación exterior de la empresa andaluza", Boletín económico de ICE, Información Comercial Española, 2688, 11-18.

De Lucio, J. J., Mínguez, R. y Álvarez, D. (2007): "El tamaño de la empresa exportadora e importadora española”, Boletín Económico de ICE, Información Comercial Española, 2908, 13-30.

Dean, D., Mengüç, B. y Myers, C. (2000): "Revisiting Firms Characteristics, Strategy and Export Performance Relationship", Industrial Marketing Management, 29, 461-477.

Diamantopoulos, A. e Inglis, K. (1988): "Identifying differences between high-and lowinvolvement exporters". International Marketing Review, 5(2), 52-60.

Evans, P. y Wurster, T. (1997): "The new economics of information", Harvard Business Review, 5, 71-82.

EXTENDA, Agencia Andaluza de Promoción Exterior (2014): Observatorio del Comercio Exterior de Andalucía de Extenda, Listado de Empresas Exportadoras 2014, recuperado de http://www.extenda.es/web/opencms/servicios/observatorio/?tab-2.

FAECTA. (2007): “Internacionalización de los Mercados. Diagnóstico de la situación de las Empresas Cooperativas Andaluzas de Trabajo Asociado", Investigación realizada por Federación Andaluza de Empresas Cooperativas, 1-85.

Fariñas, J.C. y Jaumandreu, J. (1995): "La encuesta sobre estrategias empresariales: características y usos", Documento de trabajo, Fundación Empresa Pública, 9508.

Fayos T., Calderón H. y Mir J. (2011): "El éxito en la internacionalización de las cooperativas agroalimentarias españolas. Propuestas de un modelo de estudio desde la perspectiva del marketing internacional”, CIRIEC-España, Revista de Economía Pública, Social y Cooperativa, 72, 43-72.

Fayos, T. y Calderón, M. H. (2013): "Principales problemas de internacionalización de las cooperativas agroalimentarias españolas", REVESCO. Revista de Estudios Cooperativos, 111, 32-59.

Fernández, M.J. (2013): "Las exportaciones como impulsoras de la recuperación de la economía española", Cuadernos de Información Económica, 234.

Fernández, M.V., Peña, I. y Hernández, F. (2008): "Factores determinantes del éxito exportador. El papel de la estrategia exportadora en las cooperativas agrarias", CIRIEC-España, Revista de Economía Pública, Social y Cooperativa, 63, 39-64.

Fernández, Z. y Nieto, M. J. (2002): "La estrategia de internacionalización de la pequeña empresa familiar", Documentos de trabajo, Economía de la Empresa, Universidad Carlos III de Madrid, recuperado de http://orff.uc3m.es/handle/10016/26. 
Fuentes, F. J., Sánchez, S. M. y Santos, L. M. (2011): “Cooperativas agroalimentarias y exportación. El proceso de internacionalización de la Cooperativa del Valle de Los Pedroches (COVAP)", REVESCO. Revista de Estudios Cooperativos, 104, 38-62.

Galán, J. I., González, J. y Galende, J. (2000): "Factores determinantes del proceso de internacionalización: El caso de Castilla y León comparado con la evidencia española", Economía Industrial, (333), 33-48.

Ganotakis, P. y Love, J. H. (2009): "RyD, Innovation and Exporting: Evidence from UK new technology based firms", recuperado de: http://eprints.aston.ac.uk/6979/1/R_D_innovation_and_exporting.pdf.

García-Canal, E., Guillén, M. y Valdés-Llaneza, A. (2012): "La internacionalización de la empresa española. Perspectivas empíricas", Papeles de Economía Española, 132, 6481.

Geldres, V.V., Etchebarne, M.S. y Bustos, L.H. (2011): "La distancia psíquica y el desempeño exportador: un reto para la pyme en la era de la globalización 1.2", Estudios Gerenciales, 27(118), 85-96.

González, J., Navarro, M. y Peña, I. (2010): "Internacionalización de empresas jóvenes innovadoras en España", Revista Europea de Dirección y Economía de la Empresa, 19 (2), 61-82.

González, X. (1999): "Inversión extranjera directa e I+D en las manufacturas", Revista de Economía Aplicada, 20, 5-28.

Grisprud, G. (1990): “The Determinants of Export Decisions and Attitudes to a Distant Market: Norwegian Fishery Exports to Japan", Journal of International Business Studies, 21(3) 469-486.

Gutiérrez, A., Morán, J.C., Belda, J.I., Sánchez-Torné I. y Pérez-Suárez, M. (2014). Informe sobre la internacionalización de la Economía Andaluza y de sus provincias y el nuevo modelo productivo, 2, Patrocinado Fundación Cajasol y la Fundación de Investigación de la Universidad de Sevilla, Ed. Instituto de Estudios de Cajasol.

Herrero, C. y Sanz, J.J. (2003): “¿Conocemos la realidad de la empresa exportadora española? La elaboración de una nueva fuente de información", Boletín Económico de ICE, Información Comercial Española, 2775.

Hollenstein, H. (2005): “Determinants of international activities: Are SMEs different?" Small Business Economics, 24 (5), 431-450.

Houghton, K.A. y Winklhofer, H. (2004): "The effect of website and e-commerce adoption on the relationship between SMEs and their export intermediaries", International Small Business Journal, 22(4), 369-388.

Izquierdo, A., Martínez, M.P. y Jiménez, A.I. (2010): “Condicionantes económicos de la adopción de una innovación por parte del consumidor: análisis de la compra de servicios online", Innovar, 20(36), 173.

Jordá, R. M. y González, R. (2009): "Binomio innovación-internacionalización y su relación con la estrategia en las empresas innovadoras localizadas en Andalucía", Scripta Nova: Revista Electrónica de Geografía y Ciencias Sociales, 13, 300.

Juliá, F.J. y Marí, S. (2003). Agricultura y desarrollo rural: contribuciones de las cooperativas agrarias, Red CIRIEC.

Kafouros, M.I., Buckley, P.J., Shapr, J.A. y Wang, C. (2008): "The role of internationalization in explaining innovation performance", Technovation, 28(1-2), 6374. 
Katsikeas, C. S., Leonidou, L. C. y Morgan, N. A. (2000): "Firm-level export performance assessment: review, evaluation, and development", Journal of the Academy of Marketing Science, 28(4), 493-511.

KPMG (2015): "Estudio del Sector Agroalimentario en Andalucía", recuperado de http://www.kpmg.com/ES/es/ActualidadyNovedades/ArticulosyPublicaciones/Docum ents/estudio-sector-agroalimentario-andalucia.pdf

Leonidou, L.C. (1995): “Export barriers: non-exporters' perceptions”, International Marketing Review, 12(1), 4-25.

Leonidou, L.C., Katsikeas, C.S. y Samiee, S. (2002): "Marketing strategy determinants of export performance: a meta-analysis ”, Journal of Business Research, 55 (1), 51-67.

López, J. (2004): “Análisis de la actividad exportadora de la empresa: una aproximación desde la teoría de recursos y capacidades", Tesis doctoral -Universidad de A Coruña.

López-Duarte, C. y García-Canal, E. (1998): "La estructura de propiedad de la inversión directa en el exterior", Investigaciones Económicas, 22(1), 19-44.

Lu, J.W. y Beamish, P.W. (2001): "The internationalization and performance of SMEs", Strategic Management Journal, 22(6-7), 565-586.

Martín, J., Rastrollo, M.A. y González, E.M. (2009): "La internacionalización de la empresa: El conocimiento experimental como determinante del resultado en mercados exteriores", Cuadernos de Economía y Dirección de la Empresa, 12(39), 123-149.

Martín-Armario, E., Acedo, F.J. y Martín-Ruiz, D. (2003): "Los frentes de investigación dominantes en Marketing", Universidad de Sevilla, recuperado de http://www.epum2004.ua.es/aceptados/279.pdf.

Medina, M.J., Mozas, A., Bernal, E. y Moral, E. (2014): "Factores determinantes para la exportación en las empresas cooperativas oleícolas andaluzas", CIRIEC-España, Revista de Economía Pública, Social y Cooperativa, 81, 241-262.

Melle, M. y Raymond, J.L. (2001): "Competitividad internacional de las Pyme industriales españolas”, Papeles de Economía Española, 88-105.

Millán, M.G. y Melián, A. (2008): "El mercado de trabajo femenino en las empresas de Economía Social de Andalucía: un análisis econométrico del perfil de la mujer trabajadora", Pecvnia: Revista de la Facultad de Ciencias Económicas y Empresariales, Universidad de León, 7, 227-256.

Monreal, J. (2009): “Análisis del Comportamiento Exportador de la Empresa Española desde el Enfoque de los Recursos y Capacidades”, Tesis doctoral - Universidad de Murcia.

Moral, E., y Lanzas, .J.R. (2009): "La exportación de aceite de oliva virgen en Andalucía: Dinámica y factores determinantes”, Revista de Estudios Regionales, 86, 45-70.

Moreno, L. y Rodríguez, D. (1998): "Diferenciación de producto y actividad exportadora de las empresas manufactureras españolas, 1990-1996", Investigación Comercial Española, 773(9), 25- 35.

Morgan, R.E., y Katsikeas, C.S. (1998): "Exporting problems of industrial manufacturers". Industrial Marketing Management, 27(2), 161-176.

Nakos, G., Brouthers, K. D. y Brouthers, L. E. (1998): “The impact of firm and managerial characteristics on small and medium-sized Greek firms' export performance", Journal of Global Marketing, 11(4), 23-47.

Nassimbeni, G. (2001): "Technology, innovation capacity, and the export attitude of small manufacturing firms: a logit/tobit model", Research Policy, 30(2), 245-262. 
Oviatt, B. M. y Mcdougall, P. P. (2005): "Defining international entrepreneurship and modeling the speed of internationalization", Entrepreneurship Theory and Practice, 29(5), 537-554.

Pérez R. B. y Carrillo B. E. (2000): Desarrollo local: manual de uso, ESIC Editorial.

Pérez, M.C. y Jiménez, M. (2012): "Dinámica territorial y economía social: una reflexión con especial referencia a Andalucía ante los cambios sociales", Revista de Estudios Empresariales, Segunda Época, 1, 40-58.

Reid, S.D. (1982): "The impact of size on export behavior in small firms", Export Management: an international context, 18-38.

Romero, I. y Rodríguez-Gutiérrez, M.J. (2014): "Sobre la internacionalización de la PYME y su contribución a la imagen exterior de España", Comillas Journal of International Relations, (1), 91-104.

Strader, T.J. y Shaw, M.J. (1997): "Characteristics of electronic markets”, Decision Support Systems, 21(3), 185-198.

Tabares, S. (2012): "Revisión analítica de los procesos de Internacionalización de las Pymes", Pensamiento y Gestión, (33), 67-92.

Vila, N. y Kuster, I. (2007): "The importance of innovation in international textile firms", European Journal of Marketing, 41(1/2), 17-36.

Westhead, P., Binks, M., Ucbasaran, D. y Wright, M. (2002): "Internationalization of SMEs: A research note", Journal of Small Business and Enterprise Development, 9 (1), 3848.

Zou, S. y Stan, S. (1998): "The Determinants of Export Performance: A Review of the Empirical Literature between 1987 and 1997," International Marketing Review, 15 (5), 333-56. 